\title{
"EVEN THOUGH": \\ ON THE DIFFERENT FUNCTIONS OF DISCOUNTING EXPRESSIONS IN PRO AND CON ARGUMENTS
}

\begin{abstract}
We often say things like "Even though X, Y" or "In spite of $\mathrm{Y}, \mathrm{X}$ ". What do we mean when we say things like this? What does it imply about the reasons involved? I will argue that there are at least some cases, namely when they are used in the conclusions of conductive arguments, where it should be seen as modifying our expression of $\mathrm{X}$ and indicating a certain kind of affect towards X, and this is characteristic of (the most interesting class of) conductive arguments. Showing that there are such uses thus shows that there are conductive arguments, or at least arguments with this characteristic feature, and, conversely, it will be shown that it is by taking the reasoning to be conductive that we can best make sense of these uses. I do not intend a comprehensive survey of all possible uses of "even though" or of all accounts of conductive arguments that have been given.

Keywords: conductive arguments, discounting expressions, moral reasoning, detachment, ambivalence, moral remainders.
\end{abstract}

\section{1. "Even though" as an argumentative indicator}

Often, we have reasons for and against a standpoint. In pro and con argumentation these reasons are listed, weighed in some way, and a conclusion drawn, which conclusions are often expressed with an "even though" clause. How do such clauses function? This leads to another question: given that such clauses mention one or more of the reasons against the standpoint, how do such reasons themselves function?

I want to show that there are two ways in which such clauses and the con reasons mentioned in them might function: rhetorically and logically. I will argue further that this marks a difference between two types of pro and con arguments: respectively, non-conductive and conductive. By giving examples where there is such a logical function, I aim to show firstly that there is such a thing as conductive arguments and secondly try to cash out 


\section{David Botting}

what this logical function is. I do not intend to give an analysis of conductive arguments. ${ }^{1}$

I will argue that the usual function is rhetorical: the arguer mentions the reason in an "even though" clause in order to indicate something about himself and/or his reasoning to his listener when presenting his reasoning, and this is what makes it rhetorical. If there were no listener, the clause would be redundant. However, it is commonly thought, following Wellman (1971), that there is a type of pro and con argumentation that he calls 'conductive', and in conductive pro and con arguments the cons are still taken to have some weight despite being outweighed by the pros, and in such arguments the function of "even though" is not rhetorical. Somehow, the cons still count against the conclusion, but not to the extent of undermining it.

These are the limits of the discussion: I am not going to discuss the use of "even though" clauses in contexts other than pro and con argumentation, nor am I going to discuss its use in all conductive argumentation - not all conductive arguments are pro and con arguments, and not all pro and con arguments are conductive. There are, then, two sub-types of pro and con arguments, namely those that are conductive and those that are not, and the "even though" clause functions differently in each, logically in the first and rhetorically in the second.

That is to say, in such conductive arguments I want to argue that the "even though" clause functions differently: logically rather than rhetorically. In fact, as will be discussed in detail later, whether or not conductive pro and con arguments exist at all rests largely on whether one can coherently suppose there to be such a logical function. By 'logical' I mean this: corresponding to the fact that the cons still seem to count against the conclusion in a piece of conductive pro and con argumentation, when I conclude "X even though Y" I express a slightly different proposition and/or attitude towards the proposition expressed by "X" than if I simply concluded "X." The presence or not of a listener is irrelevant to the appropriateness of expressing or having such an attitude, and this distinguishes the logical use from the rhetorical use.

Exactly how to characterise the difference between " $\mathrm{X}$ " and " $\mathrm{X}$ even though $\mathrm{Y}$ " is a tricky business. It is tempting to think of it as a 'qualifier' in Toulmin's sense of expressing, for example, a more tentative attitude towards the conclusion, but I doubt this. Nor do I think that "even though" functions as some kind of logical connective between the propositions expressed by "X" and "Y". I hope to make some inroads into the problem by consideration of conductive pro and con argumentation in moral con- 
texts. In such contexts I will argue that the "even though" clause functions to express a moral remainder like regret, the cause of which regret is the con; we regret that we cannot act in a way where good acts - acts which the weight of moral reasons favour - have some morally bad consequences that we have reason to avoid, consequences whose occurrence are reasons against performing the act. If this is right, then both " $\mathrm{X}$ " and "X even though Y" express the same psychological mode and the same propositional content, namely asserting the truth of " $\mathrm{X}$ ", and the difference between them, indicated by "even though Y", is in the "felt quality' of the attitude. This 'felt quality', I will argue further, has an explanatory role that would otherwise be missing. It is appropriate to have an attitude with this felt quality, i.e., the attitude expressed by "X even though Y", whereas it would be less appropriate to have the same attitude without that felt quality, i.e., the attitude expressed by "X". Because of this "X even though $\mathrm{Y}$ " rather than " $\mathrm{X}$ " is the appropriate conclusion for conductive reasoning to draw.

One of the problems this account will encounter is that it is not clear whether there can be moral remainders either! True, the account could still be the correct one if we only think (perhaps mistakenly) that there are such remainders and seek to express them; but I want not only to explain why we might use "even though" clauses when we express the conclusions of our moral reasoning, but that we are right to do so, that in doing so our language has latched onto moral facts about the situation that would not have been latched onto had we neglected to add the "even though" clause.

If this account of the function of "even though" clauses in conductive pro and con arguments is correct, then, since it differs from the function it takes in non-conductive pro and con arguments - which is to say, it is not a rhetorical use - then this points to there being a genuine distinction between two types of pro and con argumentation, and validates taking conductive arguments (or at least those conductive arguments that are pro and con) as a genuine kind of argument. In short, what marks out conductive pro and con arguments as a distinct class is precisely the fact that cons somehow retain their weight after the conclusion has been drawn, since this is not the case for arguments of other kinds. As we will see later, this has been discussed, not altogether happily in my view, in terms of 'detachment' - if we detach the conclusion, having decided that this is what is favoured by the balance of reasons, then there seems to be no point in mentioning the outweighed reasons, except the rhetorical one of making manifest to an interlocutor that these reasons have been considered. Conduction is then argued to have incompatible commitments: to detachment and to cons 


\section{David Botting}

retaining their weight. If we try to solve the problem by releasing the commitment to cons retaining their weight by arguing for a rhetorical function in mentioning cons, then we avoid incompatibility at the cost of removing the very thing that marked out conductive arguments as a distinct class in the first place. Not only do I need to argue, then, for the logical function of "even though" in these kinds of arguments, but I will show later that this is not incompatible with other commitments.

Illustrative (but not exhaustive) of the non-conductive types of pro and con arguments in which "even though" clauses function rhetorically are arguments when we are reasoning with generalizations subject to exceptions, since the fact or possibility of something being an exception is obviously a reason against what is generally true being true in this specific instance. "Even though" occurs especially in putatively fallacious instances of this, that is to say, when we are accusing the arguer of a fallacy of sweeping generalization. Here is an example of the fallacy from S. Morris Engel (1976: 66): "Everyone has a right to his own property. Therefore, even though Jones has been declared insane, you had no right to take away his weapon".

The impression this example gives is a curious one. For the argument to be an instance of fallacious reasoning, it must be the case that the arguer must think that the general statement that everyone has a right to their own property is subject to exceptions, since if he thinks that it is exceptionlessly true, then there is no error in drawing the conclusion that everyone has a right to their own property, even in Jones's case. Charging the arguer with bad reasoning involves attributing to the arguer a belief that the argument is not exceptionless; otherwise, the criticism would not be that he has reasoned badly, but that he has reasoned correctly from a false (because taken to be exceptionless when it is not) premise. Also, how can whoever makes the charge of fallacy explain the arguer's saying "even though Jones has been declared insane"? Why would someone who takes the generalization to be exceptionless mention at all something that he does not take to be an exception?

Thus, I deny any idea that the fallacy of sweeping generalization is driven by some sort of equivocation between exceptionless generalizations and those 'generic' generalizations subject to exceptions. If an arguer takes a generalization to be exceptionless when it is not, then he is not equivocating or reasoning badly. It is a perfectly mundane case - that can obtain of any argument - of being wrong about a premise.

On the other hand, if he does take the general statement as subject to exceptions, then how can the arguer say "even though Jones has been declared insane, you had no right to take away his weapon"? The arguer 
seems to mention an exception only to treat it as not being an exception. I do not see how, if he takes insanity as an exception to the general rule, he can then go on to conclude - contrary to the exception explicitly stated - that Jones has a right to his own property. People who bring the charge of fallacy here often accuse the arguer of ignoring exceptions, but I do not see how it can be possible to attribute ignorance of an exception to an arguer when the arguer mentions it explicitly! But then we get the same question as before: why mention at all something that he does not take to be an exception? What does the "even though" clause indicate?

The use of the clause seems to be for rhetorical purposes. We must imagine that this occurs in the context of a real or anticipated disagreement with an objector. For the objector, being insane is an exception or what Toulmin calls a 'rebuttal'; or at least, the arguer anticipates that being insane might be thought to be such a condition. Now there are two possibilities.

One possibility is that the speaker is claiming that the general statement really is exceptionless against someone who is claiming that it has exceptions. Often our general principles have consequences that we find counter-intuitive, but we nonetheless choose to "bite the bullet" and accept those consequences. Here, there is a substantive disagreement as to the nature of the general statement, with the arguer taking it as exceptionless, but anticipating that an objector might take it to be subject to exceptions, insanity being one such.

The other possibility is that there is agreement that the general statement is subject to exceptions, but there is a substantive disagreement about whether insanity actually is one of those exceptions. By saying "even though Jones has been declared insane" the arguer once again indicates that he does not consider this an exception, which is a substantial disagreement about whether something is an exception, and does not justify an accusation of fallacy.

These are the valid uses of the clause, and they are all rhetorical. In a while, I will try to give an account of a non-rhetorical use, and perhaps that use could apply here also. I am not trying to claim that the uses I describe are the only possible uses, but I do claim that if it is used to describe a genuine case of fallacious reasoning, then it is implausible that anyone reasons in this way, so it is more plausible to take the clause as indicating a substantive disagreement of some kind, and not to suggest an error in reasoning. That is not to say that if someone did take something as an exception, but did not treat it as such, it would not be an error in reasoning - clearly it would. It just does not seem plausible that anyone would actually do this, and so passages like the example given are better interpreted 


\section{David Botting}

not as cases of fallacious reasoning, but as expressions of substantive disagreement. $^{2}$

The "even though" clause thus seems to play a rhetorical function, that is to say, it expresses disagreement and identifies the locus of disagreement. In itself, it does not seem to head off disagreement in any way: the speaker has not given any reasons why Jones's being insane should not be treated as an exception.

It is in the conductive types of pro and con arguments in which "even though" clauses do not function rhetorically; from this we may conclude that there is something rather distinctive about how the reasons against a standpoint function in conductive arguments. If the use turned out, in the end, to be just another rhetorical use, this would cast serious doubt over whether there was such a thing as conductive arguments as a distinct class.

Before going on, I want to clear up a common misunderstanding. It has become common in argumentation studies to regard all pro and con argumentation to be conductive, but this is not Wellman's view. Weighing pros and cons is not definitive of conduction, for there are other forms of reasoning in which weighing takes place, including inductive reasoning where positive and negative instances may be weighed against each other (Wellman 1971: 58). (Similarly for reasoning with exceptions, except here the exceptions are taken as decisive and as vetoing the pros. $)^{3}$ What positively characterizes conductive reasoning, as already intimated, is that the weight of a con seems to behave differently then in other kinds of reasoning: a con has weight against the conclusion without affecting the weight of the pros, because the relevance of each premise to the conclusion is potentially independent of the relevance of all the others, and this is so even after the conclusion has been drawn. Thus, we may say "Martin Luther King is a fine man because, in spite of occasional arrogance, he is an unselfish and courageous worker for his fellowman" (Wellman 1971: 53). Here "in spite of" like "even though" - introduces a possible exception or reason against Martin Luther King's being a fine man, namely his arrogance. Here, though, the imputation is quite clear: this is not an exception. However, the arguer does not seem here to be simply heading off potential disagreement about whether this is an exception, rather, this reason still seems to have some weight, even after the conclusion has been drawn, and this weight is being expressed in the conclusion by adding the "even though" clause.

I now need to consider the question of whether this commitment is incompatible with detachment. Jonathan Adler argues that cons having weight even after the conclusion has been drawn is inconsistent with drawing 
a conclusion at all. Having taken the pro considerations to be sufficient for drawing a conclusion, how can it still be relevant to mention a con, or take that con to have some kind of weight? Yet it seems characteristic of this kind of conductive reasoning that it be described, and even that its conclusion be described, in this kind of way, that is to say, with an "in spite of" or "even though" clause. Adler likens the matter to detachment in deductive logic: when we state the conclusion of deductive reasoning we simply state the conclusion and not the premises that led us to that conclusion, except possibly for rhetorical reasons. Adler considers whether it might not be for similarly rhetorical purposes that we mention reasons against our conclusion in conductive reasoning:

In the case of Conductive Arguments the 'even though's' are part of the speaker's communicative intent. The conventional implication is that these reasons against the conclusion are outweighed. But it also conveys that the speaker has taken account of not just favorable considerations, but unfavourable ones. The speaker (arguer) is not subject to familiar biases like one-sidedness. (Adler 2013: 247)

If "even though" is used only for rhetorical purposes, then there is no particular reason to think of conductive arguments as a unique kind of argument; it is any kind of argument in which there are reasons both for and against the standpoint. But this, we have seen, is not how Wellman defines 'conductive', and makes 'conductive' into an empty term.

I suspect that in ordinary cases of pro and con argumentation, this is, in fact, the case. Consider the case we examined earlier, where I argued that the putative exception was mentioned for a rhetorical purpose. The rhetorical purpose seems to be different, namely that of indicating one's argumentative virtue, rather than that of identifying a locus of disagreement. But it is still, fundamentally, a rhetorical purpose, and rhetorical purposes seem to be the sole function of "even though" clauses in these types of argument.

This is not, however, how defenders of conductive argument would understand their "even though" clauses. Whether or not defenders take what J. Anthony Blair, in his reply to Adler, calls a no detachment view of conductive arguments, it still seems to be the case that they want to be able to say things like "Martin Luther King is a fine man because, in spite of occasional arrogance, he is an unselfish and courageous worker for his fellowman" and have a non-rhetorical use of "in spite of"; if this were just another rhetorical use, this would not distinguish conductive arguments from other kinds. Blair suggests: 
Given that the considerations on one side are sufficient to justify drawing (and detaching) the conclusion, what non-rhetorical purpose is served by include [sic] the outweighed counter-considerations in the model of the argument? (We have already discussed the rhetorical reasons that Adler identifies as plausible.) After all, aren't the counter-considerations simply shed during the reasoning process that led the reasoner to his or her conclusion, when he or she judged them to be outweighed by the considerations on the other side? One good reason for including both the pros and the cons in our arguments is that doing so is epistemically responsible. On the assumption that we have an obligation to accurately and honestly convey the strength of our evidence or other grounds for our conclusions in our arguments, mentioning the counterconsiderations that we judge had to be overridden to detach a conclusion indicates fully the nature of the support we take that conclusion to have.

The mention of the con considerations indicates that the argument is weaker than it would be thought to be if only the pro considerations had been mentioned. For example, "She deserved first prize in the literary contest because, although her prose style did not stand out, her plot was so ingenious and her characters so interesting." is not as strong a case for first prize as, "She deserved first prize in the literary contest because her plot was so ingenious and her characters so interesting." (Blair 2016: 124 [my italics])

But how is this a "non-rhetorical purpose"? A good reason for including both the pros and the cons when we convey or present our arguments is that we present ourselves as epistemically responsible when we do so and do not make out those arguments to be stronger than they are. The cons play no logical function once the matter has been settled. This is effectively Adler's point, and Blair's response misses the wood for the trees. ${ }^{4}$ Moreover, if they have no such logical function, this is not a distinct kind of argument, for the type of argument depends on its logic, not on its rhetorical mode of presentation. To repeat the point, the cons appear still to have a weight even after the conclusion has been drawn, and this weight affects the logical support for the conclusion, and it is precisely because of this fact that conductive arguments, if they exist, are distinct from other kinds. If there is such a thing as conductive reasoning, the purpose of "even though" is not rhetorical but logical in some way that is distinct from the kind of negative support that you would get, for instance, from negative instances in an inductive argument, which in contrast would cease to have any logical weight once the conclusion had been drawn.

We might wonder whether there are such logical, non-rhetorical uses of "even though", and hence whether there are such things as conductive arguments as distinguished from pro and con arguments in general. We only really have examples to go on. However, in the next section I will give some 
examples from ethical discourse where "even though" or "in spite of" are used in in a way that does seem to indicate a con's persisting logical weight after the conclusion has been drawn without, however, apparently weakening that conclusion. I will also show that, once the reasoning is accepted to be conductive, no conclusion can be drawn about what meta-ethical theories best fit the data of ethical discourse.

\section{Moral "remainders"}

In this section I will discuss, through our moral phenomenology in regard to particular cases, how "even though" clauses and the like function in certain cases of moral reasoning, viz., as a linguistic sign of some kind of affect or 'felt quality' accompanying the attitude, rather than as modifying in some way the psychological mode or propositional content of the attitude. I will speculate that this is evidence not only that this makes the moral reasoning conductive, but that this is the key to giving an explication of the logical function we need. The drawback of what I will essay here is that it is not clear how this generalizes outside of the moral context, unless we want to suppose that it is only moral reasoning that is conductive in this way. ${ }^{5}$ This drawback aside, if I can show a logical function for "even though" with respect to conductive moral reasoning, this does show a fortiori that there is such a thing as conductive pro and con arguments distinct from other kinds of pro and con arguments and it will be a counter-example to sceptical claims about conduction like Adler's.

The first example concerns Gary Watson's (2004a) "Robert Harris" example. Without going into too many details, Harris was convicted of murdering two people, and what distinguished him was his complete lack of remorse. Watson argues that we have strongly negative reactive attitudes against Harris and consider him guilty. Yet, Watson says, we begin to experience some kind of ambivalence when we learn about his abusive childhood.

How can we account for what we feel in this situation? Do we change our reactive attitude, perhaps for another in the "cooler" part of the spectrum of reactive attitudes, or choose to take a non-reactive attitude instead, where we consider Harris to be not fully responsible and needing to be "managed" rather than punished? Perhaps some people would react that way, but it does not seem to be forced upon us by considerations of appropriateness; it does not seem inappropriate or unjustified to have the hotter reactive attitudes, or to blame Harris. Our initial reactive attitudes remain and we do not withdraw them or, in general, think them to be any less appropriate, that 


\section{David Botting}

is to say, we do not consider Harris to be any less guilty. Moreover, if it were another attitude that should take the initial attitude's place, what we would experience is simply a succession of two attitudes, and not ambivalence.

Another possibility might be that rather than two attitudes in succession, we have two attitudes at the same time that conflict with each other and this is the cause of our ambivalence. We might imagine two ways in which an account like this might be cashed out. Firstly, we might say that we have one attitude in which we find Harris guilty, and another in which we do not find him guilty, and this is why we feel ambivalence when we find him guilty. However, this does not seem to match the psychological evidence: we consider the moral reasoning to be over, and to have concluded that Harris is guilty. Secondly, we might consider the second attitude to be a kind of meta-level comment on the first attitude. Often, this stems from the concern to avoid being hypocritical: we think something like "If I had had the kind of background that Harris had, would I be any less callous?", and even if one answers this question negatively, one can understand why others could not. Watson himself suggests that there is an intuition of "There but by the grace of God go I" in the one who holds the reactive attitude. I think this suffers from the same problem as the last, which is that it does not explain the ambivalence. If we decide to abandon the reactive attitude, as he seems to suggest, then the "There but by the grace of God go I" intuition might explain it, but we have not explained ambivalence itself.

Both approaches share the same general problem: they explain why we might change our minds, but they do not explain why we are "in two minds", that is to say, it does not explain our ambivalence; furthermore, it does not seem inconsistent to be ambivalent in the way described and yet have no inclination to change our mind. Our moral reasoning is still at an end, and we do not have to re-open it. ${ }^{6}$

But why should we assume that ambivalence is an error, or that it indicates a tension that needs to be resolved? Couldn't ambivalence, or perhaps we might say blaming ambivalently, be the appropriate response?

To recap: it does not seem, as we might otherwise be tempted to suppose, that we are experiencing two attitudes that conflict with each other. But we do seem to qualify our judgment and our reactive attitude in some way, and I return to Watson's initial suggestion that our psychology seems to lead to its being the initial reactive attitude that is modified in some way, but not, it seems, in a way that undermines it, that is to say, we do not consider it any less justified for all that. Having more or less exhausted the other possibilities, I propose that what this modifies in the reactive attitude is not its propositional content or the strength with which it is held, but 
something like a 'felt quality'. To indicate this felt quality of ambivalence we express our judgment using an "in spite of" clause, e.g., "In spite of Harris's upbringing, he acted morally reprehensibly when he killed those people." Although the felt quality is not propositional, obviously the verbal expression of it is propositional, and we should take the conclusion as such to be this entire expression. Since I would also claim that in some cases an ambivalent attitude is the correct attitude to have and the attitude to which one's moral reasoning should lead, I would say also that the reasoning that leads to such a conclusion is normative - ambivalence is not some kind of defect that we would not have were we perfect moral reasoners whose reactive attitudes always matched up to the moral facts.

I suggest that this makes more sense if we take the reasoning involved to be conductive. As we have seen, what is characteristic of conductive reasoning is that cons seem to retain a logical weight even after the conclusion has been drawn. I suggest that this is because they qualify the conclusion in something like the way described in the Harris example, and this is what we indicate by "even though" and "in spite of" clauses. Equally, the linguistic data of using these clauses in these non-rhetorical ways seem to weakly confirm this hypothesis. If it were deductive, then, once the matter of Harris's guilt was settled, there would be something odd or at least superfluous about any such clause.

Ambivalence seems to be in the same family as what is called in ethical theory a "moral remainder." These occur in situations where, whatever we do, we do something for which it would be justified for someone else to hold a reactive attitude such as resentment towards us. This is most vividly exhibited in cases where we are choosing the lesser of two evils, or one of two equally evil evils, especially if it is through no fault of our own that we are in this situation. Even though the moral reasoning has been settled, and, we may suppose, on the right moral decision, it still seems justified for the agent to feel regret or even guilt about carrying it out. This could also be the case where the choice is between two good things; it may be appropriate to feel regret at not being able to do one good thing because doing a better thing deprived one of the opportunity.

Virtue ethicists claim that remainders present a problem for moral rationalists such as utilitarians and deontologists. After all, the moral deliberation has taken place and no-one really questions whether the conclusion reached is the right one. Why, then, should one feel regret when acting in accordance with correct moral deliberation? Granted, it may be pragmatically useful to feel this way; for example, unless one feels guilty about the forced violation of a moral rule, one could get into bad habits and violate 


\section{David Botting}

the rule also in situations where one is not forced to. So it is useful for inculcating psychological habits that one feel, e.g., guilty. But the utilitarians and deontologists are committed to saying that the agent is not, as a matter of fact, guilty, and so the feelings of guilt, however justified they may be instrumentally, appear to have got the basic facts of the situation wrong.

Virtue ethicists can avoid this because they do not identify acts that are morally good with acts that are in accordance with correct moral deliberation: the lesser of two evils is still an evil, and not a good. We can still say that the decision was a good one, but the act itself was not, and because it was not, it is justifiable for us to feel guilt, for those we have harmed to feel resentment towards us, and for us to make some kind of attempt to make reparation or amends. ${ }^{7}$ Michael Stocker puts it like this:

In determining that the act is to be done, they [the reasons against the act, i.e., its bad-making features - DB] are taken into account. They tell against that act, but not with enough force to make it overall wrong. However, by focusing on these features as dirty, they are given moral weight all over again, now on their own, and are taken as reasons against doing that act and reasons for regretting doing it. They remain dirty even though justified. [my italics] (Stocker 1992: 52-53)

The reasons against the act appear to be double-counted, but we could rephrase this as saying that they retain their weight even after the conclusion has been drawn. This makes what Stocker says here very similar to what was said about conductive argument, and Stocker uses an "even though" clause to express it. The moral weight of negative features is allowed for by their continuing logical weight. If so, the existence of moral remainders does not prove anything about what over-arching meta-ethical theory best accords with our moral psychology, but only something about the logic of our moral reasoning. Nor does it prove anything about whether what the agent has done is an evil or, as utilitarians and deontologists insist, good. Certainly, the linguistic data do not seem to prove anything either way, and, taking the linguistic data as indicative of our psychology, nor does the psychological data. The moral is: any theory at all can cope with moral remainders and their expression in "even though" clauses, if its reasoning is conductive.

The virtue ethicist Rosalind Hursthouse more or less seems to concede this, even without requiring conductive reasoning: utilitarians and deontologists could express the remainder, e.g., as "x-and-apologise-or-makerestitution-as-soon-as-possible" (Hursthouse 1995: 629). In other words, utilitarians and deontologists need not deny remainders but, by building the remainder into the conclusion, capture the same moral psychology as the 
virtue ethicists. ${ }^{8}$ Their failure to do this leads, says Hursthouse, to a number of false dilemmas. For example, a utilitarian will object to a Kantian that her theory commits her to $\mathrm{X}$ being the right thing to do, when it is clearly the wrong thing to do, and in return the Kantian will tell the utilitarian that his theory commits him to $\mathrm{Y}$ being the right thing to do, when it is clearly the wrong thing to do. If the Kantian could say " $\mathrm{X}$ is the right thing to do, but I regret having to do it and will attempt to make amends to those I have harmed" then the force of the counter-example is lessened, and mutatis mutandi for the utilitarian. Although they do not generally do this, Hursthouse seems to allow that they could, that there is no theoretical inadequacy that rules it out.

Hursthouse attributes the failure to accommodate remainders to committing one of several possible fallacies. The first is a false dilemma, by taking the dilemma to

be "either $\mathrm{x}$ is the morally right act to do here (without qualification) and $\mathrm{y}$ is the one that's morally wrong or y is the morally right act etc." They overlook the third possibility of, e.g. "Well, they are both pretty awful, but (supposing the dilemma is resolvable) $\mathrm{x}$ isn't quite as bad as y." This assumption that, in any case of moral dilemma or conflict, one side must be unqualifiedly morally right and the other plain wrong runs very deep in everyday thought. (Hursthouse 1995: 622)

The problem with this is that it presupposes Hursthouse's own definition of what is a "morally right act." I wonder whether anybody faced with the kind of dilemma Hursthouse has in mind would deny that all of his options are "pretty awful" - after all, their comparative awfulness has factored into his reasoning. He would, however, maintain that the lesser of two evils is a morally right act, at least in the circumstances.

The second fallacy Hursthouse appeals to is the following:

Suppose we have a moral dilemma which is resolvable $-\mathrm{x}$ is worse than $\mathrm{y}$. Then the decision to do y rather than $\mathrm{x}$ is, in the circumstances, the right decision. Moreover (supposing the decision to have been made on the moral grounds that $\mathrm{x}$ is worse than $\mathrm{y}$ ), it is a moral decision, or one that has been made morally. So it is the "morally right decision" or the "right moral decision," and this is one way in which we use those clauses.

Now suppose we have a morally right act - a good deed. As such, it is an act that merits praise rather than blame, an act that an agent can take pride in doing rather than feeling unhappy about, the sort of act that decent, virtuous agents do and seek out occasions for doing. Moreover, agents are praised for deciding to do such acts, can take pride in the decision - it's the sort of decision that decent virtuous agents make, even if, through no fault of 


\section{David Botting}

their own, the act doesn't come off. Suppose it does not come off, well, that is a pity, but still, we say, they made the "morally right decision", the "right moral decision"; good for them. And here, we use those clauses in a second, different, way. (Hursthouse 1995: 623)

Hursthouse is claiming that we sometimes equivocate between different senses of "morally right decision", but I find this claim peculiar: as far as I can see, the "morally right decision" is the one that is in accordance with correct moral reasoning in both cases, and the fact that in the second case it "doesn't come off" seems beside the point and not to indicate a second use of the phrase. Hursthouse's point can probably be preserved by noting that what accords with a "morally right decision" is not necessarily a "morally right action" or "good deed" since we could be choosing between two morally wrong actions. In this case, Hursthouse has misspoken, and the distinction she wants to draw is not between two uses of "morally right decision", but between an action's being right in the sense of being the best, morally, we can do in the circumstances, in contradistinction to being a good deed deserving of praise. Morally right acts - acts deserving of praise - do not leave remainders, but acts that are not deserving of praise, but nonetheless accord with morally right decisions, should, in Hursthouse's view, leave remainders. So, whoever (like the Kantian) thinks that what is in accordance with a morally right decision is necessarily a morally right action, and that morally right actions do not leave remainders, thinks that there cannot be remainders. ${ }^{9}$

Against Hursthouse, I would argue that both of these objections beg the question against the utilitarian or deontologist who thinks that what is in accordance with a morally right decision is necessarily a morally right action; in the circumstances, the utilitarian or deontologist might say, the act, though horrible, even deserves praise. There is a strange asymmetry in our intuitions here that is actually unprincipled: it is considered principled and praiseworthy to sacrifice oneself for the greater good, but to sacrifice another, even if we consider it ultimately justified, is not generally taken to merit the same kind of praise, and the agent is expected to sacrifice himself with some level of dignified equanimity, but, if forced to sacrifice others, is expected to feel ravaging, soul-scouring guilt.

However, I do not think that the utilitarian or deontologist has to take this strategy because it all assumes that morally good actions do not leave remainders, and I see no reason to accept this. Hursthouse herself says that sometimes I can do a good thing, like help at the scene of an accident, and yet still find it appropriate to make amends to someone whom I failed to 
meet as a result of my stopping to help. Only moral acts for which there are no moral reasons at all against them fail to leave moral remainders. In this case, it is the fact that the utilitarian or deontologist does take this strategy when he or she does not have to (that is to say, is not theoretically committed to it) that constitutes his or her error in failing to accommodate remainders. As Hursthouse seems to say, utilitarianism and deontology are not theoretically inconsistent with remainders, so if utilitarians or deontologists deny remainders, this is not because of their theory, but because of committing a fallacy in applying it. The fallacy is not, however, what Hursthouse says that it is, but the failure to reason conductively.

\section{Reasoning with remainders}

Presumably, Hursthouse takes the reasoning involved to be deductive, but with a conclusion that includes the remainder, or that expresses an intention to make amends for the remainder. I want to suggest instead that the reasoning involved is conductive. Strictly speaking, nothing I have said so far proves this. One of the problems is that I have not shown that the use of an "even though" clause is needed for a non-rhetorical purpose. All the reasons that Hursthouse says that theorists ought to mention remainders seem to be rhetorical: to lessen the effect of putative counterexamples, for instance. It is not obvious, therefore, that the cons have any logical weight.

In the quote from Stocker, however, there seems to be at least an indication that these cons do have this kind of weight; at the very least, they are said to have moral weight. If they do have a logical weight, then this does seem to indicate that the reasoning is conductive. So, it is important for my claim that "even though" has a non-rhetorical use that captures somehow the logical weight of the cons even after the conclusion has been drawn. Conductive reasoning gives us some kind of semi-formal apparatus that allows for this, but it cannot itself explain it.

I think that the cons have logical weight and it is correct to mention them because sometimes a qualified statement can be explanatory of the unqualified statement, and this because a qualified action can be explanatory of an unqualified action. Take cases in the philosophy of action that exhibit so-called primary deviance. Consider Davidson's example of two climbers, where the one above considers whether to drop the rope so that his fellowclimber falls to his death, and perhaps even forms the intention to do so. Having these thoughts so discombobulates him that he actually does drop 


\section{David Botting}

the rope, despite never actually acting on the intention. Intuitively, the climber has not intentionally killed his fellow climber or dropped the rope, even though his intention was causally responsible for his dropping the rope. This seems to be a case of causal deviance, but where can we locate the deviance? Dropping the rope is presumably the basic action; it is what is directly caused by the climber's having the intention.

I think the way to avoid this problem is to deny that dropping the rope $i s$ the basic action. Rather, we should say that some qualified version of this action - such as dropping the rope nervously - is the basic action, and this action is not intentional, there being no intention to drop the rope nervously. This explains the action of dropping the rope; if one were to ask the climber why he dropped the rope, he would say "I was nervous," and he is less likely to have done so had he not been nervous, even in the case where he had formed the intention but not acted on it. The qualified action expressed in the qualified statement "He dropped the rope nervously" is more basic than and explanatory of the unqualified action expressed in the unqualified statement "He dropped the rope".

Equally, I think that something like "I resent Robert Harris ambivalently" is more basic than "I resent Robert Harris", not simply because it is the first conclusion that we draw, but because in some sense it is more likely that I blame Robert Harris on the supposition that I blame him ambivalently than if that supposition were false. This claim might seem false. After all, did we not initially just blame Robert Harris? Doesn't any ambivalence imply that we are less likely to blame Robert Harris if anything, and not more? Yes, but this is because initially we were not aware of Harris's upbringing. Once we have become aware of the cons, it becomes explanatory of X-ing despite the cons that we make it in some kind of affective state that consideration of the cons has brought us to. There is less distance between "I do not resent Robert Harris" and "I resent Robert Harris ambivalently" than there is between "I do not resent Robert Harris" and "I resent Robert Harris". To put it slightly differently, someone who did cease to resent Robert Harris would find more understandable someone who still resented Robert Harris, but ambivalently, than someone who felt no different at all on learning of Harris's upbringing and did not modify their resentment in any way. Making the qualification explicit makes the attitude of resentment more understandable.

Similarly, I think, with regret and guilt. When we indicate regret or guilt over doing $\mathrm{X}$ we are as much explaining our $\mathrm{X}$-ing as justifying it. The corresponding affective states are explanatorily relevant and even, in some cases at least, causally relevant to our action, since we might not have 
X-ed had we not been in that state. The "even though" clause is not just dispensable, then, but is in fact the correct description of the basic action, even when this 'action' is just having an attitude as the result of reasoning.

\section{Conclusion}

In this paper I do not want to take any particular stand on how best to analyse conductive argumentation: my aim is only to describe what seems to be most characteristic of it, and to establish whether there is any argumentation matching this description. I argued that what was characteristic of it was not simply that it involved possible exceptions to a generalization or pros and cons generally, but more narrowly that the cons seemed to retain a logical weight against the conclusion even after the reasoning had judged them to be outweighed by the pros. This logical weight is indicated by "even though", "in spite of", or some other kind of discounting expression mentioning the cons.

Adler (2013) questioned whether there could be any argumentation like this, and said that we only mention the cons for rhetorical reasons, in which case there was nothing distinctive about conductive argumentation; Blair (2016) responded that there could be argumentation like this, but in the end he only offered a different rhetorical use of the "even though" clause, and did not show that the cons mentioned there continued to have any logical weight. It really does not matter whether the conclusion is detached or not, for although we may choose to mention the cons when we utter the conclusion of an argument, when that conclusion is not detached, this still does not mean that the cons continue to have logical weight in those arguments, and defenders of conductive argumentation do think that the cons continue to have logical weight and their uses of "even though" to be non-rhetorical whether their accounts of conductive argumentation involve detachment or not. Although I have not argued it in any detail here, I think that this way of responding to Adler's criticism is mistaken in its conception. Rather, I think that the entire conclusion including the "even though" has to be taken as the conclusion, and this because firstly mentioning the cons indicates a kind of felt quality of the attitude resulting from the reasoning, and secondly because this qualified attitude is more basic than, and explanatory of, the unqualified attitude - it is not that the 'real' conclusion is " $\mathrm{X}$ " and " $\mathrm{X}$ even though $\mathrm{Y}$ " is just an intermediate result; certainly, we can infer "X" from "X even though Y", but this is a corollary of the real conclusion. It is appropriate to have that attitude with that par- 


\section{David Botting}

ticular felt quality, and if we expressed this just by saying " $\mathrm{X}$ " it might be inferred that this felt quality was missing, and inappropriately so.

I do not expect this to settle the debate whether there can be any conductive argumentation in principle. More telling is if there actually does seem to be argumentation like this in fact. I have given two examples that, if they are correctly describing the phenomenology of the situation, do seem to fit this description of conductive reasoning, and seem to support the conjecture that the logical weight of the cons survives in the form of a felt quality: in one case this quality was ambivalence, in another case regret and/or guilt. Also, I argued that this quality was appropriate irrespective of whether X-ing is "good". While the debate between virtue ethicists on the one hand and utilitarians and deontologists on the other, has been over whether X-ing is good, where it is assumed that there is no moral remainder if it is good since then the reactive attitude is inappropriate, I argue that there can be a moral remainder whether it is good or not, and that the presence of remainders does not indicate that X-ing is not "good", but that the reasons against $\mathrm{X}$-ing qualify the $\mathrm{X}$-ing and the decision to $\mathrm{X}$. In short, it indicates conductive reasoning. Hursthouse is quite right to suggest that utilitarians and deontologists have no theoretical inadequacy with regard to moral remainders, but wrong to attribute their denial of moral remainders to the kind of fallacious reasoning she finds there. If they reason badly, it is only because they do not reason conductively and think that remainders, like the cons themselves, must be nullified when they are judged to be outweighed by the pros.

\section{N O T E S}

${ }^{1}$ In saying that conductive arguments form a distinct class, I am not committed to conductive arguments having an analysis that makes them sui generis. For the purposes of this paper, which is not concerned with analysis of conduction, this is a subject about which I can afford to be agnostic. A selection of theoretical accounts of conductive arguments are to be found in Blair and Johnson (2011). My own take on the theoretical issues involved here can be found in Botting (2012).

2 Botting (forthcoming) gives a more detailed analysis of the fallacy of sweeping generalization.

${ }^{3}$ It is worth observing that it would be unusual in the inductive case to weigh the case for X and say "X, even though there are negative instances of X"; if X is being advanced as a universal generalization, then saying that it has negative instances would be self-contradictory, and if X is advanced as a statistical generalization, then saying that it has negative instances would be pointless. It would be equally unusual to say when we have, for example, taken Jones's insanity as an exception, "Since Jones is insane, you had a right to take away his weapon, even though everyone has a right to his own property" for much the same reasons. Whatever is included in the "even though" clause would be either redundant or make the statement self-contradictory. We do not usually 


\section{"Even Though": on the Different Functions of Discounting Expressions...}

express our conclusions or reasonings with "even though" clauses in ordinary pro and con argumentation. If we do, it is for rhetorical purposes such as those described above, or for showing explicitly what reasons and potential objections against the standpoint we have taken into consideration.

4 A large part of Blair's defence is that Adler has misunderstood what defenders of conductive arguments mean by "non-conclusive", and perhaps he has. Nonetheless, the fact remains that defenders of conductive arguments want to make a claim in the form "X even though Y" whether they 'detach' X or not, and do not take the function of "even though" to be rhetorical. Adler's more fundamental point is to ask, sceptically, how this makes sense once $\mathrm{X}$ has been settled on as the right answer, and in the extract above Blair echoes this complaint. Even so, by focussing so strongly on what is meant by "non-conclusive" Blair neglects this fundamental point; moreover, the function Blair gives this clause is rhetorical anyway, being concerned with wanting to satisfy an interlocutor's doubts about the arguer's being epistemically responsible. This is a kind of use that Adler could concede without it affecting his argument. Nor is Blair's analysis descriptively accurate of what defenders of conductive arguments mean by "even though". Perhaps the idea is that we want to describe our reasoning, just as when we sit an exam we are always encouraged to show our "workings out". But we can give an argument for our conclusion without showing our reasoning, as I think Blair anticipates; he wants to say that it is epistemically responsible to show our working out, but this still restricts the purpose of "even though" to the presentation of the argument to an interlocutor and not to the relation of the conclusion to the premises or the distinctive way those premises behave.

5 This is not so far-fetched, given that Wellman's concerns are with the structure of arguing about claims in ethics.

${ }^{6}$ In the end, Watson also falls back on a two attitude view, supposing that the ambivalence is an error brought about by confusing two "faces" of responsibility (Watson 2004b): although we can attribute one kind of responsibility to Harris, the responsibility that we attributed to him via the reactive attitude is unjustified. This is in tension with what he says earlier, that it seems like it is the original attitude of blame that undergoes some kind of modification without being any less appropriate.

7 Arguably, it would not be appropriate for a third person to blame the agent. Usually, what we feel for someone who finds themselves in this situation through no fault of their own is not blame but pity. This is an interesting asymmetry between the third-person perspective and the first and second-person perspectives.

8 I find Hursthouse's overall strategy unclear. On the one hand, she seems to raise the issue of dealing with moral remainders as a plus point for virtue ethics and a minus point for utilitarian and deontological ethics. But if the latter could deal with moral remainders, if only they reasoned non-fallaciously, then this seems to undercut her own position. It is not because virtue ethics is a better theory, but because virtue ethicists are better reasoners (!), that they are better able to accommodate moral remainders. But see later for an interpretation more charitable towards Hursthouse.

${ }^{9}$ Now Hursthouse seems to be saying that utilitarian and deontological ethics is inconsistent with moral remainders after all, and its commitment to denying them is not just a case of fallacious reasoning but a theoretical commitment. This seems inconsistent with what she said before. Perhaps what she thinks is that there is a pre-theoretical commitment - which is, however, incorrect in her view - that acts according with the right moral decision are always and inevitably morally right acts, and that it is this mistaken idea that leads reasoners to utilitarian and deontological views rather than to virtue ethics, and to the denial of moral remainders. But this relies on the view, as will become clear, that morally right acts cannot leave remainders, and I do not see why anyone should be committed to this, either theoretically or pre-theoretically. 


\section{R E F E R E N C E S}

Adler, J. (2013). Are conductive arguments possible? Argumentation 2\%: 245-257.

Blair, J. A. (2016). A defence of conduction: a reply to Adler. Argumentation 30(2): 109-128.

Blair, J. A. \& Johnson, R.H. (eds.). (2011). Conductive argument: an overlooked type of defeasible reasoning. London: College Publications.

Botting, D. (forthcoming). The fallacy of sweeping generalization. Presented at the 20th NCA/AFA Conference on Argumentation in Alta, Utah, U.S.A on 20th to 23rd July 2017. In Winkler C. (ed.) Networking Argument, Selected Papers from the 20th Biennial Conference on Argumentation (forthcoming), National Communication Association.

Botting, D. (2012). Wellman's typology of arguments. Studies in Logic, Grammar and Rhetoric 28(41): 23-43.

Engel, S. M. (1976). With good reason: an introduction to the informal fallacies. New York: St. Martin's Press.

Hursthouse, R. (1995). Fallacies and moral dilemmas. Argumentation 9: 617-632.

Stocker, M. (1992). Dirty hands and conflicts of values and of desires in Aristotle's Ethics. In Plural and Conflicting Values. Oxford: Clarendon Press, 51-84.

Watson, G. (2004a). Responsibility and the limits of evil. In Agency and answerability, 219-259. Oxford: Clarendon Press.

Watson, G. (2004b). Two faces of responsibility. In Agency and answerability, 260288. Oxford: Clarendon Press.

Wellman, C. (1971). Challenge and response: justification in ethics. Carbondale, IL: Southern Illinois University Press. 